\title{
Contemporary Challenges
}

The Global Crime,

Justice and Security Journal

\section{Femicide:}

\section{A Global Phenomenon Requiring an Intersectional Social Constructivist Approach}

\section{Sabrina Knap}

MSc in International Relations, University of Edinburgh

\begin{abstract}
Femicide is a relatively new area of study that was first introduced in 1976 . Since then, there has been a push by many scholars to develop the field further, despite some arguments made that femicide is not as important of an issue given the relatively low rates of female homicides compared to male homicides. This article reviews three levels of analysis - micro, meso, and macro - and discusses culture and class as two contributing factors to femicide, illustrating that femicide is a complex global phenomenon that requires a multilateral and intersectional approach to be better understood. It concludes that by understanding and deconstructing certain social and institutional structures, we will be better equipped to understand femicide as a phenomenon and create more effective systems and legislation for a safer global society.
\end{abstract}

Keywords: femicide, female victimisation, gender-based violence, patriarchal society, intersectionality 


\section{Introduction}

Femicide is a term, first coined by Diana Russell in 1976 during the First International Tribunal on Crimes against Women to describe the killing of females by males because they are women. ${ }^{1}$ While there is extensive research on the gender-neutral term homicide, which looks at motives, psychology, and other factors, few have taken a gendered perspective to specifically address the murder of women. ${ }^{2}$ Russell's work started the formal conversation on female murders which has continued to progress over the past several decades. Caputi and Russell further developed the term femicide as "the misogynous killing of women by men motivated by hatred, contempt, pleasure, or a sense of ownership over women, rooted in historically unequal power relations between women and men." Some scholars argue that femicide does not demand its own separate area of study, given the fact that men experience higher rates of homicide than women. ${ }^{4}$ However, in a rejection of this position, the study of femicide seeks to bring attention to the various systematic and societal factors of patriarchy and oppression that lead to women's deaths. ${ }^{5}$ Too often femicide is brushed aside as a cultural norm or a crime of passion, but there is not one single cause of femicide that we can point to. ${ }^{6}$ A multilateral approach is necessary to adequately analyse the various socially constructed factors at play on different levels. This approach allows us to understand how and why women are murdered in order to ultimately assist in preventing it on a broader scale.

In this article, I first describe the three main levels of analysis that should be considered in femicide research - micro, meso, and macro - and cite examples of how each level uniquely contributes to the gender-biased murder of women. Secondly, I address two of the most

\footnotetext{
${ }^{1}$ Magdalena Grzyb, Marceline Naudi, and Chaime Marcuello-Servós, "Femicide Definitions," in Femicide across Europe: Theory, Research and Prevention (Bristol: Policy Press Shorts Policy \& Practice, 2018), 17-31.

${ }^{2}$ Nadera Shalhoub-Kevorkian, "Reexamining Femicide: Breaking the Silence and Crossing 'Scientific' Borders," Signs: Journal of Women in Culture and Society 28, no. 2 (2003): 581-608, https://doi.org/10.1086/342590.

${ }^{3}$ Jane Caputi and Diana E.H. Russell, "Femicide: Speaking the Unspeakable," Ms.: The World of Women 1, no. 2 (1990): 34.

${ }^{4}$ Heather Agnew, "Reframing 'Femicide': Making Room for the Balloon Effect of Drug War Violence in Studying Female Homicides in Mexico and Central America," Territory, Politics, Governance 3, no. 4 (2015): 428-445, https://doi.org/10.1080/21622671.2015.1064826.

${ }^{5}$ Consuelo Corradi et al., "Theories of Femicide and Their Significance for Social Research," Current Sociology 64, no. 7 (2016): 975-995, https://doi.org/10.1177/0011392115622256.

${ }^{6}$ Karen Stout, "Intimate Femicide: An Ecological Analysis," The Journal of Sociology \& Social Welfare 19, no. 3 (1992): 29-50.
} 
relevant factors that should be examined to understand femicide - culture and class - in order to create effective preventative measures and begin to chip away at the patriarchal structure that harms women in these contexts. I conclude with a discussion on how the social construction of society has played the primary role in why femicide is an issue, offering suggestions to reconstruct systems and norms in place to make life safer for women around the world.

\section{Levels of Analysis}

An ecological framework is essential when approaching the study of femicide, as there is no single factor to explain the phenomenon. There are countless personal, communal, and societal aspects at play that contribute to femicide and violence against women generally. In analysing the various actors, both individual and systematic, scholars can begin to deconstruct the influences that lead to femicide in varied contexts. As Shalhoub-Kevorkian maintains, we need to "analyze both the macrocontext and process of social transformation and the microcontext of local cultural specificities." Many of these aspects are interconnected at different levels and perpetuate social and cultural norms that can prove to be dangerous to women.

\subsection{Micro}

The micro level of analysis is primarily concerned with the "individuals' psychological organisation, psychosocial habits and interactions," as well as the close relationships in a victim's life. ${ }^{8}$ This framework looks at the demographics of the victim such as age, race, and the victim/offender relationship, especially as it relates to the family, given the fact that interpersonal homicide is one of the leading causes of femicide globally. In a 2019 study, it was reported that $58 \%$ of the 87,000 women intentionally killed in 2017 were murdered at the hands of an intimate partner or other family member. ${ }^{9}$ Although women only represent $19 \%$ of total homicides, they represent $64 \%$ of family-related homicides and $82 \%$ of intimate partner

\footnotetext{
${ }^{7}$ Shalhoub-Kevorkian, "Reexamining Femicide," 602.

${ }^{8}$ Christiana Kouta et al., "Understanding and Preventing Femicide Using a Cultural and Ecological Approach," in Femicide across Europe: Theory, Research and Prevention, ed. Shalva Weil and Consuel Corradi (Bristol: Policy Press Shorts Policy \& Practice, 2018), 53-69, 59-60.

9 UNODC, “Gender-Related Killing of Women and Girls," Global Study on Homicide 2019, 2019.
} 
homicides. ${ }^{10}$ The micro level analysis looks through personal and familial lenses to explain individualised femicides.

While each murder has different contextual circumstances, at the micro level we can begin to assess the factors contributing to the different types of femicide, such as sex-selective abortion, female infanticide, and homicide. For example, in many East and South Asian countries such as China and India, there is an implicit preference for male children. ${ }^{11}$ Daughters are often seen as an economic burden with little value in comparison to sons, especially to poorer families, which often leads to sex-selective abortions and female infanticides. ${ }^{12}$ Although we are unable to definitively determine the rate of sex-selective abortions and female infanticides due to their nature, we can see patterns by examining the sex ratio of populations in countries where these practices are common, as male birth rates are significantly skewed compared to global averages and an estimated "1.5 million girls go missing at birth" every year. ${ }^{13}$ Further discussion on class implication in these cases is to follow.

In cases of interpersonal violence leading to femicide, there are several elements that can overlap for both familial and romantic relationships, such as poverty or overt misogyny that can take the form of emotional or economic abuse. Although various types of abuse can be identified, physical abuse is one of the most prevalent themes present in these cases and is often recognised and even noted before the femicide occurs. ${ }^{14}$ While interpersonal homicides can often be characterised as "crimes of passion," 15 there are, in fact, many warning signs and contributing characteristics to these murders, suggesting that patterns can be identified earlier

\footnotetext{
${ }^{10}$ UNODC, "Gender-Related Killing of Women and Girls."

${ }^{11}$ Rosemary Barberet, Women, Crime and Criminal Justice: a Global Enquiry (London: Routledge, 2014).

${ }^{12}$ Barberet, Women, Crime and Criminal Justice; Kouta et al., "Understanding and Preventing Femicide Using a Cultural and Ecological Approach."

${ }^{13}$ Asian Centre for Human Rights, "Female Infanticide Worldwide: The Case for Action by the UN Human Rights Council," 2016, 2.

${ }^{14}$ Anna C. Baldry and Maria J. Magalhães, "Prevention of Femicide," in Femicide across Europe: Theory, Research and Prevention, ed. Shalva Weil and Consuelo Corradi (Bristol: Policy Press Shorts Policy \& Practice, 2018), 71-92; Jacquelyn C. Campbell et al., "Risk Factors for Femicide in Abusive Relationships: Results From a Multisite Case Control Study." in Domestic Violence, ed. Mangai Natarajan (London: Routledge, 2007), 135-43.

${ }^{15}$ Crime of passion is in reference to a crime that is committed in the "heat of passion" in response to a provocation, as opposed to one that was premeditated or deliberate, according to "Crime of Passion," Legal Information Institute, Cornell Law School, accessed April 1, 2021, https://www.law.cornell.edu/wex/crime_of_passion.
} 
on. Looking at the personal elements of femicide therefore enables researchers to understand the nuanced dynamics contributing to the phenomenon and could ultimately help implement prevention strategies.

\subsection{Meso}

The meso level of analysis explores the community influence, examining settings such as the neighbourhood, workplace, or schools to illuminate some of the localised pressures and systems that contribute to femicide. At the meso level, there is often a perpetuation of oppressive standards, stereotypes, and a general disregard for female life, facilitating a culture in which female murders are under-investigated and/or ignored. ${ }^{16}$ The complex relationship between the public and private sphere is one of the most vital aspects in understanding femicide at the meso level. As will be demonstrated, in communities that condone or even encourage femicide in cases such as the murder of sex workers and honour killings, oppressive standards are routinely put on women in the public sphere that have consequences in the so-called private sphere.

One example of a meso level influence on femicide can be seen through the characterisation of sex workers. The rate of femicide against sex workers is relatively high around the world but is especially prevalent in many Western and Latin American countries, such as the United States and Mexico. Female sex workers are often disregarded as humans being worthy of life, given their line of work. ${ }^{17}$ They are considered "public women" who work outside the home and spend time in "typically deemed male spaces," and may therefore be reasoned as objects for men to do with as they please. ${ }^{18}$ There is some evidence to suggest this idea can also extend to women who are more independent, whether that be financially with a stable job or in their behaviours more generally such as frequenting bars, in strong patriarchal societies. ${ }^{19}$ For example, in some regions in Mexico, femicides are often under-investigated as police insist

\footnotetext{
${ }^{16}$ Agnew, "Reframing 'Femicide."”; Michaela Rogers, "Transphobic 'Honour'-Based Abuse: A Conceptual Tool,” Sociology 51, no. 2 (2016): 225-240, https://doi.org/10.1177/0038038515622907; Lorena P.A. Sosa, "Inter-American Case Law on Femicide," Netherlands Quarterly of Human Rights 35, no. 2 (2017): 85-103, https://doi.org/10.1177/0924051917708382.

17 Jane Caputi, The Age of Sex Crime (London: Women's Press, 1987).

18 Agnew, "Reframing 'Femicide," 431.

19 Agnew, "Reframing 'Femicide."”
} 
that these women were "probably prostitutes," asking family members questions about the woman's drinking or dating behaviours, insinuating "they probably had it coming." ${ }^{20} \mathrm{By}$ maintaining this narrative, police investigations often leave families without answers about the seemingly random murders of the women in their family.

Another example of the meso level influence on femicide can be understood through honour killings, which are predominantly observed in South Asian and Middle Eastern countries. Honour killings are the ritual murders of family members for bringing perceived "shame" to the family and disproportionally affect women as men are the ones who typically define the terms of "honour" in such communities. ${ }^{21}$ In cases of "dishonourable" acts, such as disobedience, seeking divorce, or adultery, public pressure builds on families in various ways, such as through the loss of business or general ostracisation, to the point that family members may take drastic measures, often resulting in murder, in order to restore honour to the family's name. ${ }^{22}$ Further discussion on the cultural implication of honour killings is to follow.

In both of these examples, there is a broad notion that violence against women is a private matter, to be handled quietly or by the family, rather than an issue of gender security or femicide. $^{23}$

\subsection{Macro}

The macro level of analysis looks more generally at the established structures and institutions in place that often contribute to the micro and meso level factors, such as the economic, social, educational, legal, and political systems of a society. ${ }^{24}$ By examining aspects such as gender equality in the context of legal, economic, and political policies, scholars can

\footnotetext{
${ }^{20}$ Agnew, "Reframing 'Femicide."”; Melissa W. Wright, "The Dialectics of Still Life: Murder, Women, and Maquiladoras," Public Culture 11, no. 3 (1999): 453-473, https://doi.org/10.1215/08992363-11-3453 ; Melissa W. Wright, “A Manifesto against Femicide,” Antipode 33, no. 3 (2001): 550-566, https://doi.org/10.1111/1467-8330.00198.

${ }^{21}$ Shalhoub-Kevorkian, "Reexamining Femicide."

${ }^{22}$ Veena Meetoo and Heidi Safia Mirza, “'There Is Nothing 'Honourable' about Hounor Killings': Gender, Violence and the Limits of Multiculturalism," in Honour, Violence, Women and Islam, ed. Mohammad Mazher Idriss and Tahir Abbas (Abingdon: Routledge Taylor \& Francis Group, 2011), 42-66; ShalhoubKevorkian, "Reexamining Femicide."

${ }^{23}$ Dandara Oliveira Paula, "Human Rights and Violence Against Women: Campo Algodonero Case," Revista Estudos Feministas 26, no. 3 (2018): 1-9, https://doi.org/10.1590/1806-9584-2018v26n358582.

${ }^{24}$ Stout, "Intimate Femicide."
} 
consider the various barriers to enter society that women face, which can ultimately put them at higher risk of femicide. The macro level analysis should include both the national and international perspective for a holistic view of society. While the national analysis can provide greater insight to a specific state's systems, it is equally important to analyse how international bodies influence or maintain these systems - for better or worse.

According to UN Women, women make up more than two-thirds of the world's 796 million illiterate people, are routinely paid less than their male counterparts, and, in many parts of the world, are unable to access adequate medical, legal, or financial support. ${ }^{25}$ Systems that inherently discriminate against women on such large scales ultimately leave them in vulnerable positions. Without proper education, women are less likely to obtain decent work; without decent work, women either become dependent on a male provider or engage in illicit markets to make ends meet. ${ }^{26}$ In largely patriarchal societies, women in situations of abuse or neglect are often unable to access different services, either for fear of retribution or a general lack of support from the systems in place. As a consequence, such women are left in the hands of their abuser, which has the potential to escalate to death. ${ }^{27}$ Examining the broader systems and institutions in place therefore not only brings the larger picture into view but can also contribute to understanding the micro and meso levels.

\section{Factors at Play}

Femicide is a complex social phenomenon that requires careful consideration of compounding factors. While gender is obviously the key component in the study of femicide, how gender interacts with other factors within various contexts needs to be better understood. Throughout all three levels of analysis, two key factors emerge as powerful influences on femicide: culture and class. While both aspects vary in how they manifest themselves, their

\footnotetext{
${ }^{25}$ UN Women, "Facts \& Figures," Commission on the Status of Women, 2012, accessed April 1, 2021, https://www.unwomen.org/en/news/in-focus/commission-on-the-status-of-women-2012/facts-and-figures.

${ }^{26}$ Scott Cunningham and Todd D. Kendall, "Prostitution, Hours, Job Amenities and Education," Review of Economics of the Household 15, no. 4 (August 2017): 1055-1080, https://doi.org/10.1007/s11150017-9360-6; Tammy L. Anderson and Philip R. Kavanaugh, "Women's Evolving Roles in Drug Trafficking in the United States," Contemporary Drug Problems 44, no. 4 (2017): 339-355, https://doi.org/10.1177/0091450917735111.

${ }^{27}$ Andrés Del Río, “\#NiUnaMenos: against Femicide in Latin America,” OpenDemocracy, published November 7, 2016, https://www.opendemocracy.net/en/democraciaabierta/niunamenos-against-femicide-inlatin-america/.
} 
similarities and differences can be instrumental in further developing research. As ShalhoubKevorkian writes, "not all women face the same destinies, nor do victims share the same socioeconomic or cultural backgrounds - all voices are partial, multiple, and contradictory. There is no totality of voices, or a totality of culture." ${ }^{28}$ In this section, I revisit several previously mentioned examples that frequently arise in cases of femicide, however doing so by analysing the topics from a cultural and class perspective in order to highlight the holistic and intersectional approach needed to adequately explain femicide.

\subsection{Culture}

As Shalhoub-Kevorkian writes, "[c]ulture is perceived by many as a powerful lens for scrutinizing society and for expanding our understanding of human thoughts and actions." 29 Culture can refer to the religion, customs, ideas, or social behaviours of a particular society. Using culture as an analytical tool to study different regions can help scholars decipher the dynamics that maintain and reproduce oppressive and abusive behaviours towards women that in turn lead to femicide. As noted above, many use the defence of cultural norms to avoid responsibility for their actions and use it "as an excuse for patriarchal structural conditions." 30 While culture differs around the world, here I specifically discuss honour killings and machismo to illustrate how certain societies use culture to maintain and justify pervasive rates of femicide.

\subsubsection{Honour killing}

Honour killings involve extreme acts of violence, usually against a woman, when an "honour code is believed to have been broken and perceived shame is brought upon the family." ${ }^{31}$ As previously noted, honour killings disproportionally affect women, given the fact that men are traditionally the creators and arbitrators of what defines honour in a community or society. Though it is difficult to capture the full extent of this phenomenon, it is estimated

\footnotetext{
${ }^{28}$ Shalhoub-Kevorkian, "Reexamining Femicide," 587.

${ }^{29}$ Shalhoub-Kevorkian, "Reexamining Femicide," 592.

${ }^{30}$ Barberet, Women, Crime and Criminal Justice, 97; Shalhoub-Kevorkian, "Reexamining Femicide."

${ }^{31}$ Meetoo and Mirza, “"There Is Nothing 'Honourable' about Hounor Killings,”" 42.
} 
that between 5,000-20,000 girls and women are victims of honour killing annually worldwide. ${ }^{32}$ "Dishonourable" acts used to justify honour killings can include circumstances such as adultery, homosexuality, insufficient dowries, divorce, or refusal to marry. ${ }^{33}$ Women can even carry the burden for the shame of male violations, such as in cases of physical or sexual assault. In these cases, additional blame can be put on women for getting pregnant after rape or incest, for being in a public space, or for "tempting" the perpetrator. ${ }^{34}$

While honour killings are more commonly observed in South Asian and Middle Eastern countries, often stereotyped to be found in Muslim communities, they cut across nearly all ethnic, class, and religious lines. ${ }^{35}$ Honour killings have been recorded around the world and have religious connections to Druze, Christians, and some Jewish groups as well. ${ }^{36}$ As Shalhoub-Kevorkian explains, "[1]ooking at femicide as a cultural traditional practice that occurs only in the 'Orient' empowers the existing patriarchal mechanisms and strategies and helps maintain such criminal behaviour as 'normal'." 37 Western countries that try honour cases of femicide have a history of granting leniency, in the form of reduced sentences or crimes, for fear of seeming culturally insensitive. ${ }^{38}$ However, doing so maintains and affirms harmful behaviours towards women. Ultimately, "[h]onour-based crimes must be recognized for what they are: crimes against women that are the products of societies structured along explicitly patriarchal lines." 39

\subsubsection{Machismo}

Machismo is a term that denotes the "traditional, sexist, patriarchal ideology expressed through gender roles that exist for the purpose of perpetuating the privileges held by one group

\footnotetext{
32 Tanya D'Lima, Jennifer Solotaroff, and Rohini Prabha Pande, "For the Sake of Family and Tradition: Honour Killings in India and Pakistan," ANTYAJAA: Indian Journal of Women and Social Change 5, no. 1 (June 2020): 22-39, https://doi.org/10.1177/2455632719880852.

${ }^{33}$ Barberet, Women, Crime and Criminal Justice; Janice Joseph, "Victims of Femicide in Latin America: Legal and Criminal Justice Responses," Temida 20, no. 1 (2017): 3-21, https://doi.org/10.2298/TEM1701003J; Kouta et al., "Understanding and Preventing Femicide."

${ }^{34}$ Meetoo and Mirza, "“There Is Nothing 'Honourable' about Hounor Killings."”

${ }^{35}$ Aisha K. Gill, "Reconfiguring 'Honour'-Based Violence as a Form of Gendered Violence," in Honour, Violence, Women and Islam, ed. Mohammad Mazher Idriss and Tahir Abbas (Abingdon: Routledge Taylor \& Francis Group, 2011), 218-231.

${ }^{36}$ Gill, "Reconfiguring 'Honour'."

${ }^{37}$ Shalhoub-Kevorkian, "Reexamining Femicide," 590.

38 Gill, "Reconfiguring 'Honour.".

${ }^{39}$ Gill, "Reconfiguring 'Honour,"' 227.
} 
(males) and the subjugation, oppression, and marginalization of another group (females)." ${ }^{40}$ The term is commonly associated with Latino culture to describe the hypermasculine and aggressive stereotype of what being a "man" means in Latin America. Machismo preserves traditional gender roles and encourages the belief that women are not worthy of respect. As Del Rio explains, "[i]t counters the recognition of women as equals, regarding ability and rights. Women are considered objects, bodies that become property of men who don't understand the world outside of this machista way of thinking." 41

Machismo within Latin America is compounded by the heavy influence of gangs and organised crime in the region. Different gang territories are equally dangerous for women. Within their own communities, women are at high risk of gang rape and murder, both of which have been documented as initiation practices. ${ }^{42}$ Within rival gangs' territories, women are at risk of vengeance killings or murder to serve as a warning sign to her local community's gang. ${ }^{43}$ As Paterson explains, "[s]uch murders can be used to show which gang has the most power. The one that does the most brutal things has the most power - all the more so if nothing happens to them as a result." ${ }^{44}$ In addition to gangs and organised crime, women are often victims at the hands of the military and police as well. Throughout many countries in the region, such as Mexico and Guatemala, the military and police are hyper-militarised in efforts to combat the "war on drugs." However, this largely unchecked power adds to violence against women and cases of femicide, as officials often perceive themselves as above the law. ${ }^{45}$ As machismo manifests itself in a myriad of ways, such as female objectification, physical abuse, or rape, it is not unfounded to make the potential link between it and femicide. Out of the top 25 states with the highest rates of femicide globally, 14 are in Latin America and the Caribbean, suggesting that machismo could be a strong relative factor. ${ }^{46}$

\footnotetext{
${ }^{40}$ Andrés Consoli and Ana R. Morales, "Machismo," in The SAGE Encyclopedia of Abnormal and Clinical Psychology, ed. Amy Wenzel (Los Angeles, CA: SAGE reference, 2017), 1992.

${ }^{41}$ Del Río, "\#NiUnaMenos: against Femicide in Latin America."

42 Agnew, "Reframing 'Femicide."”

43 Agnew, "Reframing "Femicide.",

${ }^{44}$ Kent Paterson, "Femicide on the Rise in Latin America," (Washington: Inter-Hemispheric Resource Center Press, 2006), https://www-proquest-com.ezproxy.is.ed.ac.uk/reports/femicide-on-rise-latinamerica/docview/209951286/se-2?accountid=10673.

${ }^{45}$ Agnew, "Reframing 'Femicide.",

${ }^{46}$ Del Río, “\#NiUnaMenos: against Femicide in Latin America.”
} 


\subsubsection{Gender Stereotyping}

Honour killings and machismo both demonstrate how culture can influence individual and community behaviour. Similarly, they both draw on broader gender stereotypes from both the masculine and feminine perspective - where men are superior and powerful, and women are weak or dehumanised as objects - in order to justify violent cultures. Culture is a socialised phenomenon that is reproduced "by various agencies, social actors and institutional settings." 47 Tactics such as slut-shaming and victim blaming are far more common in cases of femicide than male homicide, and regularly devalue the life and worth of women. ${ }^{48}$ Although culture is varied around the world, using it as a justification to perpetuate gender stereotypes or "cultural norms" that can have deadly effects is extremely dangerous.

\subsection{Class}

Social class is another important factor to consider when studying femicide, both in relation to the victims and perpetrators. Poorer populations tend to see higher rates of femicide and less productive investigations that produce convictions. ${ }^{49}$ Factors typically associated with lower social classes include unemployment or unstable work, low-wages, and dependency (either on the state or another person). In some developing countries, women are devalued as workers and are therefore more cost-effective for low-skilled labour, often out-pricing men for jobs. ${ }^{50}$ Men can feel threatened by a rapid social change and the breakdown of traditional gender roles by the loss of wages to women and act violently in retaliation. ${ }^{51}$ Furthermore, unemployment can leave men with idle time that, in some cases, builds up frustration or leads to substance abuse. A study conducted in the United States determined that the strongest risk factors for intimate personal femicide was the abuser's lack of employment, illicit drug use, and access to firearms. ${ }^{52}$ Given this lack of steady or well-paying work, femicide is often more expressly linked to lower economic classes.

\footnotetext{
${ }^{47}$ Baldry and Magalhães, "Prevention of Femicide," 84.

${ }^{48}$ Rae Taylor, "Slain and Slandered: A Content Analysis of the Portrayal of Femicide in Crime News," Homicide Studies 13, no. 1 (February 2009): 21-49, https://doi.org/10.1177/1088767908326679.

49 Joseph, "Victims of Femicide in Latin America: Legal and Criminal Justice Responses."; Matthias Nowak, "Femicide: A Global Problem," Small Arms Survey, 2012; Sosa, "Inter-American Case Law on Femicide."

${ }^{50}$ Agnew, "Reframing 'Femicide.",

${ }^{51}$ Stout, "Intimate Femicide: An Ecological Analysis."

${ }^{52}$ Campbell et al., "Risk Factors for Femicide in Abusive Relationships."
} 
In addition to retaliatory- or resentment-based femicide, there is a similar trend of young and poor women being targeted in Latin America due to the impunity many gang members enjoy and the "authorities' strong tendency to gender stereotyp[e]." 53 As cited above, the patriarchal idea of "public women" generally goes hand-in-hand with victim blaming. If a woman's body is found in a poor area of town, it is regularly assumed that she was either a prostitute or drug addict and the violence is therefore considered justified. ${ }^{54}$ Police and government officials frequently disregard these cases and avoid putting in the time or resources to investigate and prosecute perpetrators, given the low status of poor women. ${ }^{55}$

Another example of class playing a noticeable role in femicide is in the cases of sexselective abortions and female infanticide. These cases are traditionally seen in poorer patriarchal societies where women are deemed an economic burden given their lack of employment opportunities later in life and the costs incurred from dowries. ${ }^{56}$ Even as children, young girls are at risk of femicide from an escalation of abuse due to the previously outlined class factors. As noted above, abuse is a common underlying theme in cases of familial femicide. A joint study between the Office of the High Commissioner for Human Rights, UNICEF, and WHO reported that "stopping violence against children requires not only sanctioning perpetrators, but also transformation of the "mindset" of societies and the underlying economic and social conditions that allow violence against children to thrive." 57 Addressing abuse could in turn prove to be a powerful tool in addressing femicide.

However, class is not a fixed factor that can alone determine at-risk women, as there are many cases of middle- and upper-class women being victims of femicide as well. Understanding the role class plays in those contexts is still relatively underdeveloped compared to research on lower-class femicides and warrants further investigation, especially considering

\footnotetext{
${ }^{53}$ Sosa, "Inter-American Case Law on Femicide," 95; Paterson, "Femicide on the Rise in Latin America."

${ }^{54}$ Agnew, "Reframing 'Femicide"”; Sosa, "Inter-American Case Law on Femicide."

${ }^{55}$ Agnew, "Reframing 'Femicide."”

${ }^{56}$ Barberet, Women, Crime and Criminal Justice: a Global Enquiry.

${ }^{57}$ Barberet, Women, Crime and Criminal Justice: a Global Enquiry, 82.
} 
the difference in public framing of those narratives. ${ }^{58}$ Although lower-class femicide is seemingly more common, it is nonetheless imperative to analyse class generally within the context of femicide in order to create effective legislation and implement social services to serve women in different situations.

\section{Other Factors}

Though culture and class are two of the most prominent factors to examine when studying femicide, they are not the only two that should be considered, nor should they be considered independently. There is a myriad of factors that contribute to the explanation of femicide in various contexts and add to the risk women face. As Sosa notes, "[i]ntersectionality addresses the layered nature of oppression and the complexity of inequality, leaving traditional one-dimensional understanding behind." 59 Within each factor are even more considerations to be taken. For example, we can look at sexual or gender identity, race, immigration/refugee status, or colonialism, all of which are common factors relevant to femicide as well. Each of these elements can be analysed alone or within the context of culture or class, and, similarly, can be observed within the various levels of analysis. Given that intersectionality creates different lived experiences, it is important to understand the nuances that arise from the cross section of different factors. Femicide is still a relatively new area of research and there remain gaps in how we approach the phenomenon. Examining assorted factors through different lenses has the potential to uncover elements we may not have even considered yet.

\section{Conclusion}

The murder of women is a pervasive problem that, in a majority of cases, stems from the patriarchal constructions of society. Femicide is "part of a sociopolitical and economic legacy that reflects a hidden machinery of oppression" that has been maintained by generations to the point that it is seen almost as human nature..$^{60} \mathrm{In}$ order to understand the make-up of societies where femicide is distinctly prevalent, scholars and legislators must deconstruct the

\footnotetext{
${ }^{58}$ Lane Kirkland Gillespie, Tara N. Richards, Eugena M. Givens, and M. Dwayne Smith. "Framing Deadly Domestic Violence: Why the Media's Spin Matters in Newspaper Coverage of Femicide," Violence Against Women 19, no. 2 (February 2013): 222-45, https://doi.org/10.1177/1077801213476457.

${ }^{59}$ Sosa, "Inter-American Case Law on Femicide," 87.

${ }^{60}$ Shalhoub-Kevorkian, "Reexamining Femicide," 582.
} 
systems and institutions in place that perpetuate violence against women and identify the weak spots to support the reconstruction of a safer society. Rather than taking a bottom-up approach, issues within existing systems must be identified and changed first to create targeted social services and implement the legal and economic sanctions needed to support and protect women in different circumstances. This is no easy feat, but it will be easier to change cultural and societal attitudes if the broader national and international institutions in place provide for a more equitable society rather than perpetuate the current patriarchal norm.

Femicide is a complex issue that requires analysis at multiple levels, with the consideration of multiple factors. Integrating this analysis allows for a more comprehensive look at the risks and causes of femicide, as factors feed in across the different levels in different ways. Understanding the intersection of various elements and dismantling certain socialisation processes can ultimately aid in creating effective legislation, and in providing valuable physical and logistical support to women around the world. While there have been modest efforts made by some legislative and legal bodies to address femicide around the world - for example, the recognition of femicide as a legal term, and the work undertaken by the UN Committee on the Elimination of All Forms of Discrimination against Women - many declarations, laws, and court judgements emphasise non-discrimination based on one factor, making no reference to multiple or intersecting forms of discrimination. ${ }^{61}$ It is therefore imperative to understand the complexity and nuances of femicide to effectively explain and subsequently address these diverse factors.

\section{Bibliography}

Agnew, Heather. 'Reframing 'Femicide': Making Room for the Balloon Effect of Drug War Violence in Studying Female Homicides in Mexico and Central America." Territory, Politics, Governance 3, no. 4 (2015): 428-45, https://doi.org/10.1080/21622671.2015.1064826.

Anderson, Tammy L., and Philip R. Kavanaugh. "Women's Evolving Roles in Drug Trafficking in the United States." Contemporary Drug Problems 44, no. 4 (2017): 339-55, https://doi.org/10.1177/0091450917735111.

\footnotetext{
${ }^{61}$ Sosa, "Inter-American Case Law on Femicide."
} 
Asian Centre for Human Rights, "Female infanticide worldwide: the case for action by the UN Human Rights Council," 2016.

Baldry, Anna C., and Maria J. Magalhães. "Prevention of Femicide." In Femicide across Europe: Theory, Research and Prevention, 71-92. Bristol: Policy Press Shorts Policy \& Practice, 2018.

Barberet, Rosemary. Women, Crime and Criminal Justice: a Global Enquiry. London: Routledge, 2014.

Campbell, Jacquelyn C, Daniel Webster, Jane Koziol-McLain, Carolyn Block, Doris Campbell, Mary Ann Curry, Faye Gary, Nancy Glass, Judith McFarlane et al. "Risk Factors for Femicide in Abusive Relationships: Results From a Multisite Case Control Study.” In Domestic Violence, edited by Mangai Natarajan, 135-143. London: Routledge, 2007.

Caputi, Jane. The Age of Sex Crime. London: Women's Press, 1987.

Caputi, Jane, and Diana E.H. Russell. "Femicide: Speaking the Unspeakable." Ms.: The World of Women, 1990.

Consoli, Andrés, and Ana R. Morales. "Machismo." In The SAGE Encyclopedia of Abnormal and Clinical Psychology, edited by Amy Wenzel, 1992. Los Angeles, CA: SAGE reference, 2017.

Cornell Law School. “Crime of Passion.” Legal Information Institute. Accessed April 1, 2021. https://www.law.cornell.edu/wex/crime_of_passion.

Corradi, Consuelo, Chaime Marcuello-Servós, Santiago Boira, and Shalva Weil. "Theories of Femicide and Their Significance for Social Research.” Current Sociology 64, no. 7 (2016): 975-95, https://doi.org/10.1177/0011392115622256.

Cunningham, Scott, and Todd D. Kendall. "Prostitution, Hours, Job Amenities and Education." Review of Economics of the Household 15, no. 4 (2017): 1055-80, https://doi.org/10.1007/s11150-017-9360-6.

D'Lima, Tanya, Jennifer L. Solotaroff, and Rohini Prabha Pande. "For the Sake of Family and Tradition: Honour Killings in India and Pakistan." ANTYAJAA: Indian Journal of Women and Social Change 5, no. 1 (June 2020): 22-39, https://doi.org/10.1177/2455632719880852.

Gill, Aisha K. "Reconfiguring 'Honour'-Based Violence as a Form of Gendered Violence." Essay. In Honour, Violence, Women and Islam, edited by Mohammad Mazher Idriss and Tahir Abbas, 218-31. Abingdon: Routledge Taylor \& Francis Group, 2011.

Gillespie, Lane Kirkland, Tara N. Richards, Eugena M. Givens, and M. Dwayne Smith. "Framing Deadly Domestic Violence: Why the Media's Spin Matters in Newspaper Coverage of Femicide." Violence Against Women 19, no. 2 (February 2013): 222-45, https://doi.org/10.1177/107780121347645. 
Grzyb, Magdalena, Marceline Naudi, and Chaime Marcuello-Servós. "Femicide Definitions." Essay. In Femicide across Europe: Theory, Research and Prevention, 17-31. Bristol: Policy Press Shorts Policy \& Practice, 2018.

Joseph, Janice. "Victims of Femicide in Latin America: Legal and Criminal Justice Responses." Temida 20, no. 1 (2017): 3-21, https://doi.org/10.2298/TEM1701003J.

Kouta, Christiana, Santiago Boira, Anita Nudelman, and Aisha K. Gill. "Understanding and Preventing Femicide Using a Cultural and Ecological Approach.” Essay. In Femicide across Europe: Theory, Research and Prevention, 53-69. Bristol: Policy Press Shorts Policy \& Practice, 2018.

Meetoo, Veena, and Heidi Safia Mirza. "“There Is Nothing 'Honourable' about Hounor Killings': Gender, Violence and the Limits of Multiculturalism.” In Honour, Violence, Women and Islam, edited by Mohammad Mazher Idriss and Tahir Abbas, 42-66. Abingdon: Routledge Taylor \& Francis Group, 2011.

Nowak, Matthias. "Femicide: A Global Problem.” Small Arms Survey, 2012.

Paterson, Kent. "Femicide on the Rise in Latin America" (Washington: Inter-Hemispheric Resource Center Press, 2006), https://www-proquestcom.ezproxy.is.ed.ac.uk/reports/femicide-on-rise-latinamerica/docview/209951286/se-2?accountid=10673.

Paula, Dandara Oliveira. "Human Rights and Violence Against Women: Campo Algodonero Case." Revista Estudos Feministas 26, no. 3 (2018): 1-9, https://doi.org/10.1590/1806-9584-2018v26n358582 .

Rogers, Michaela. “Transphobic 'Honour'-Based Abuse: A Conceptual Tool.” Sociology 51, no. 2 (2016): 225-40, https://doi.org/10.1177/003803851562290.

Río, Andrés Del. “\#NiUnaMenos: against Femicide in Latin America.” OpenDemocracy, Published in November 7, 2016.

https://www.opendemocracy.net/en/democraciaabierta/niunamenos-against-femicidein-latin-america/.

Shalhoub-Kevorkian, Nadera. "Reexamining Femicide: Breaking the Silence and Crossing 'Scientific' Borders." Signs: Journal of Women in Culture and Society 28, no. 2 (2003): 581-608, https://doi.org/10.1086/342590.

Sosa, Lorena P.A. "Inter-American Case Law on Femicide." Netherlands Quarterly of Human Rights 35, no. 2 (2017): 85-103, https://doi.org/10.1177/092405191770838.

Stout, Karen. "Intimate Femicide: An Ecological Analysis." The Journal of Sociology \& Social Welfare 19, no. 3 (1992): 29-50.

Taylor, Rae. "Slain and Slandered: A Content Analysis of the Portrayal of Femicide in Crime News." Homicide Studies 13, no. 1 (February 2009): 21-49, https://doi.org/10.1177/1088767908326679.

UNODC. "Gender-Related Killing of Women and Girls." Global Study on Homicide 2019, 2019. 
UN Women. "Facts \& Figures." Commission on the Status of Women, 2012. Accessed April 1, 2021, https://www.unwomen.org/en/news/in-focus/commission-on-the-status-ofwomen-2012/facts-and-figures.

Wright, Melissa W. "The Dialectics of Still Life: Murder, Women, and Maquiladoras." Public Culture 11, no. 3 (1999): 453-73, https://doi.org/10.1215/08992363-11-3-453.

Wright, Melissa W. “A Manifesto against Femicide.” Antipode 33, no. 3 (2001): 550-66, https://doi.org/10.1111/1467-8330.00198. 